\title{
Safety and utility of endoscopic ultrasound-guided fine-needle aspiration of focal splenic lesions: a retrospective analysis
}

\author{
Surinder S. Ranaa, Vishal Sharmaa, Ravi Sharmaa, Radhika Srinivasan ${ }^{b}$, Rajesh Guptac \\ Postgraduate Institute of Medical Education and Research (PGIMER), Chandigarh, India
}

\begin{abstract}
Background Fine-needle aspiration (FNA) of focal splenic lesions (FSL) is usually done under ultrasound (US) or computed tomography guidance. Endoscopic US (EUS), because of its ability to provide high-resolution images, can be used for aspirating FSL. We studied the safety and efficacy of EUS-guided FNA of FSL.

Methods We performed a retrospective analysis of patients with FSL undergoing EUS-guided FNA over the last six years.

Results EUS-guided FNA was performed in 16 patients (age: $28-43$ years; male: 11 ). A 22-G needle was used in 13 patients, a 25-G needle in 2 patients, and a 19-G needle in 1 patient. All patients had abdominal pain, with 6 patients also having fever. On EUS, 8 patients had focal hypoechoic lesion/ lesions, whereas 8 patients had focal cystic lesion/lesions. The size of the focal lesions ranged from $0.8-10 \mathrm{~cm}$. EUS-guided aspiration was performed successfully in all patients. The cytology was adequate in all patients and a diagnosis was established in 13 (81\%) patients. The final diagnosis in patients with hypoechoic lesions was tuberculosis in 6 patients and sarcoidosis in 2 patients. The final diagnosis in patients with cystic lesions was pseudocyst in 5 patients and simple cyst in 3 patients. One patient with splenic pseudocyst had a massive hemorrhage from a splenic artery pseudoaneurysm 7 days after FNA. No other major complication was encountered.
\end{abstract}

Conclusion EUS-guided FNA of FSL is safe and provides adequate material for cytological examination, even in the case of small lesions.

Keywords Spleen, endoscopic ultrasound, fine-needle aspiration, tuberculosis, sarcoidosis, pseudocyst, cytology

Ann Gastroenterol 2017; 30 (4): 1-5

\section{Introduction}

Focal splenic lesions (FSL) are relatively rare and are caused by a variety of benign and malignant etiologies [1,2]. Studies from western countries have reported a preponderance of malignant etiologies causing FSL [1,2]. However, in tropical countries like India, various benign infectious diseases, such

Departments of a Gastroenterology (Surinder S. Rana, Vishal Sharma, Ravi Sharma); 'Cytology (Radhika Srinivasan); 'Surgery (Rajesh Gupta), Postgraduate Institute of Medical Education and Research (PGIMER), Chandigarh, India

\section{Conflict of Interest: None}

Correspondence to: Dr Surinder Singh Rana, Department of Gastroenterology, PGIMER, Chandigarh 160 012, India, Tel.: +91 172 2541044, Fax: +91 172 2744401, e-mail: drsurinderrana@gmail.com

Received 6 March 2017; accepted 23 May 2017; published online 1 June 2017

DOI: https://doi.org/10.20524/aog.2017.0167 as kala-azar, tuberculosis, and malaria, are responsible for the majority of FSL [3]. Correct diagnosis of etiologies causing FSL requires histological evaluation; previously, many of these patients required histological evaluation of a splenectomy specimen for correct diagnosis [4]. However, with recent advances in imaging techniques, FSL are being accurately diagnosed using image-guided fine-needle aspiration cytology (FNAC). Initially, percutaneous image-guided splenic aspiration was believed to be more risky, because of the increased risk of bleeding from a hematopoietic organ like the spleen $[5,6]$. However, many subsequent studies have reported an increased diagnostic yield, as well as the safety of imageguided fine-needle aspiration (FNA) of FSL [7-9].

Image-guided FNA can be performed using transabdominal ultrasound (US) or computed tomography (CT). Endoscopic US (EUS)-guided FNA is a recent addition to the diagnostic armamentarium for organs that are adjacent to the gastrointestinal tract. EUS allows high-resolution imaging of the adjacent organs with no hindrance from the bowel gases and thus helps in detection as well as sampling of even small lesions 
in a safe and controlled manner [10]. However, there is limited published experience on the safety and accuracy of EUS-guided FNA of FSL, with the majority of reported cases involving patients with solid malignant FSL $[11,12]$. In this retrospective study, we report the safety and efficacy of EUS-guided splenic FNA in patients with both solid and cystic FSL.

\section{Patients and methods}

We carried out a retrospective analysis of the patients with FSL undergoing EUS-guided FNA over the last six years. The clinical, laboratory and imaging findings of each of these patients were retrieved from the record database. Informed consent was obtained from the patients prior to EUS-guided FNA. The protocol for retrospective analysis was approved by the institutional ethics committee. These splenic lesions were located near the hilum, were small and difficult to sample under USG guidance, were not visualized on transabdominal US, or yielded inconclusive findings on initial US-guided FNA. The patients with splenic pseudocysts underwent EUS-guided aspiration as a part of the treatment plan, using transmural drainage alone or in combination with endoscopic transpapillary drainage. EUS-guided FNA was performed in patients with normal clotting studies and platelet counts that were obtained within $24 \mathrm{~h}$ of the procedure.

\section{EUS-guided FNA procedure}

EUS-guided FNA was performed with the patient under conscious sedation with intravenous midazolam $(2-5 \mathrm{mg})$. A linear scanning echoendoscope (EG-3870 UTK linear echoendoscope, Pentax Inc., Tokyo, Japan, or UCT180 linear echoendoscope, Olympus Optical Co. Ltd., Tokyo, Japan) was used at a frequency of $7.5 \mathrm{MHz}$. The spleen and FSL were evaluated in detail on EUS, with special emphasis on size, echogenicity and vascularity. EUS-guided FNA was then performed using a 19-, 22-, or 25-G needle (Cook Endoscopy, Winston-Salem, NC, USA). All EUS examinations were performed by an experienced endosonologist (SSR). A 19-G needle was used for aspirating large cystic lesions with echogenic contents, whereas a $22-$ or $25-G$ needle was used for sampling other lesions, at the discretion of the endoscopist. Prophylactic antibiotics (intravenous ciprofloxacin) were given to patients with cystic lesions, whereas no antibiotics were given to patients with solid splenic lesions.

EUS imaging of the spleen was performed from the stomach; the echoendoscope was placed across the gastroesophageal junction and then rotated clockwise until the spleen was visualized. The lesions were characterized as cystic or solid based on the EUS appearances, with anechoic lesions being characterized as cystic and hypoechoic/hyperechoic lesions being characterized as solid lesions. Once the lesions were characterized, an appropriate path for FNA was chosen using color Doppler to exclude the presence of intervening blood vessels. EUS-guided FNA was performed using a suction technique; one to two transmural needle punctures were made and aspirated material was sent for cytology and microbiology. The samples were smeared on glass slides and sent for cytological examination, as there was no on site cytopathologist. The cystic lesions were completely emptied and the fluid aspirated was sent for cytological, microbiological and biochemical tests. Patients with cystic lesions received post-procedure oral antibiotics.

Post-procedure, the patients were kept under observation for $6 \mathrm{~h}$ and then discharged. They were reassessed the next day in the outpatient clinic for any complications. The patients were treated according to the final diagnosis reached after analysis of the clinical, imaging and cytological/biochemical/ microbiological results. Patients with pancreatic pseudocysts were treated further by endoscopic/radiological or surgical methods.

\section{Results}

During the study period, EUS-guided FNA was performed in 16 patients (age: $28-43$ years; mean age: $35.5 \pm 5.6$ years; male: 11 ) (Table 1). All patients had abdominal pain on presentation and $6(38 \%)$ patients also had fever. Of these 16 patients, US-guided FNA was inconclusive in 2 patients, lesions were too small for US-guided FNA in 4, while the FNA was close to the hilum in 3 patients or not well visualized on US in 2 patients. The spleen was well visualized on EUS in all 16 patients. Eight patients had focal hypoechoic lesion/lesions (Fig. 1), whereas 8 patients had focal cystic lesion/lesions (Fig. 2). The size of the hypoechoic FSL ranged from $0.8-1.5 \mathrm{~cm}$ (mean: $1.1 \pm 0.3 \mathrm{~cm}$ ), whereas cystic lesions measured between 0.6 and $10 \mathrm{~cm}$ (mean: $5.5 \pm 2.8 \mathrm{~cm}$ ). Two (25\%) patients with hypoechoic FSL had associated intraabdominal as well as mediastinal lymphadenopathy, whereas

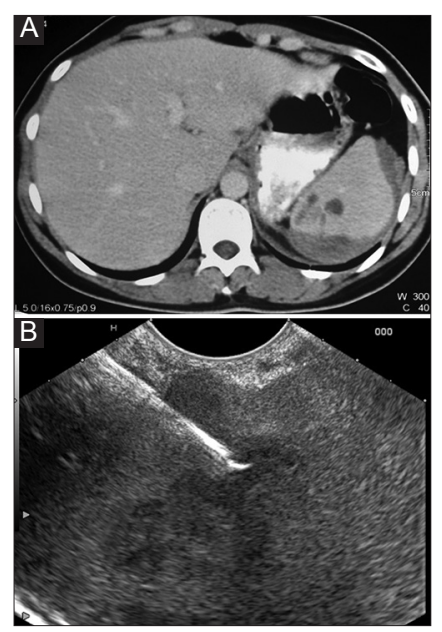

Figure 1 (A) Computed tomography scan of abdomen: multiple hypodense focal lesions in spleen with minimum perisplenic fluid. (B) Endoscopic ultrasound-guided fine-needle aspiration of focal hypoechoic splenic lesion 
Table 1 Demographic, clinical and endoscopic ultrasound profile of patients with splenic lesions

\begin{tabular}{|c|c|c|c|c|c|c|c|}
\hline Age/Sex & Symptoms & $\begin{array}{l}\text { Morphology of } \\
\text { lesion }\end{array}$ & $\begin{array}{l}\text { Size }(\mathrm{cm}) \\
\text { (largest) }\end{array}$ & $\begin{array}{l}\text { Needle } \\
\text { used }\end{array}$ & $\begin{array}{l}\text { No. of } \\
\text { passes }\end{array}$ & $\begin{array}{l}\text { Cytological/Biochemical } \\
\text { finding }\end{array}$ & $\begin{array}{l}\text { Final } \\
\text { diagnosis }\end{array}$ \\
\hline $39 / \mathrm{M}$ & Pain, fever & Multiple, hypoechoic & 1.5 & $22 \mathrm{G}$ & 2 & Granuloma & Tuberculosis \\
\hline $32 / \mathrm{M}$ & Pain & Multiple, hypoechoic & 0.8 & $22 \mathrm{G}$ & 2 & Granuloma & Sarcoidosis \\
\hline $28 / \mathrm{F}$ & Pain & Single, anechoic & 5.0 & $22 \mathrm{G}$ & 1 & Non-diagnostic & Simple cyst \\
\hline $38 / \mathrm{F}$ & Pain & Multiple, hypoechoic & 1.4 & $22 \mathrm{G}$ & 2 & Granuloma, acid-fast bacilli+ & Tuberculosis \\
\hline $35 / \mathrm{M}$ & Pain & Single anechoic & 5.0 & $22 \mathrm{G}$ & 1 & Elevated amylase and lipase & Pseudocyst \\
\hline $28 / \mathrm{M}$ & Pain & Multiple, hypoechoic & 0.6 & $22 \mathrm{G}$ & 2 & Granuloma & Sarcoidosis \\
\hline $34 / \mathrm{F}$ & Pain, fever & Multiple, hypoechoic & 1.2 & $22 \mathrm{G}$ & 2 & Granuloma & Tuberculosis \\
\hline $42 / \mathrm{M}$ & Pain, fever & Multiple, hypoechoic & 1.0 & $22 \mathrm{G}$ & 2 & Granuloma, acid-fast bacilli+ & Tuberculosis \\
\hline $32 / \mathrm{M}$ & Pain, fever & Single anechoic & 9.0 & $19 \mathrm{G}$ & 1 & Elevated amylase and lipase & Pseudocyst \\
\hline $42 / \mathrm{M}$ & Pain, fever & Single anechoic & 10.0 & $22 \mathrm{G}$ & 1 & Elevated amylase and lipase & Pseudocyst \\
\hline $34 / \mathrm{M}$ & Pain & Single anechoic & 6.0 & $22 \mathrm{G}$ & 1 & Elevated amylase and lipase & Pseudocyst \\
\hline $46 / \mathrm{M}$ & Pain & Single anechoic & 4.0 & $22 \mathrm{G}$ & 1 & Elevated amylase and lipase & Pseudocyst \\
\hline $28 / \mathrm{M}$ & Pain, fever & Multiple, hypoechoic & 1.2 & $25 \mathrm{G}$ & 2 & Granuloma, acid-fast bacilli+ & Tuberculosis \\
\hline $32 / \mathrm{F}$ & Pain & Multiple, anechoic & 1.4 & $22 \mathrm{G}$ & 1 & Non-diagnostic & Simple cyst \\
\hline $43 / \mathrm{M}$ & Pain & Multiple, hypoechoic & 1.2 & $25 \mathrm{G}$ & 2 & Granuloma & Tuberculosis \\
\hline $36 / \mathrm{F}$ & Pain & Single anechoic & 4.0 & $22 \mathrm{G}$ & 1 & Non-diagnostic & Simple cyst \\
\hline
\end{tabular}

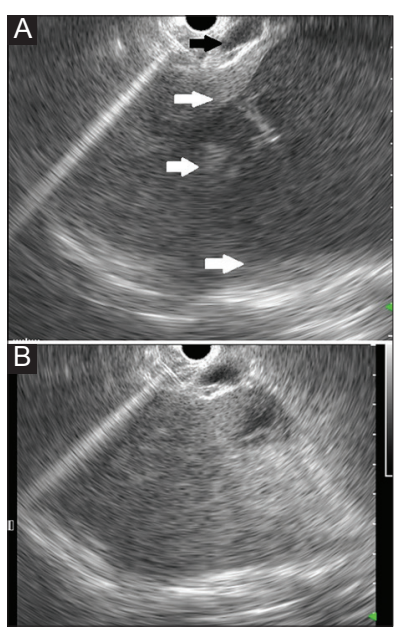

Figure 2 (A) Endoscopic ultrasound-guided aspiration of splenic cystic lesion (white arrows). Splenic vein noted at hilum (black arrow). (B) The splenic cyst completely emptied

the remaining 6 patients had isolated splenic lesions. Five patients with cystic lesions had associated changes of acute $(n=1)$ or chronic $(n=4)$ pancreatitis, whereas the remaining 3 patients had no other abnormality on EUS.

EUS-guided aspiration was performed successfully in all 16 patients. A $22-G$ needle was used in 13 patients, a 25-G needle in 2 patients, and a $19-\mathrm{G}$ needle in 1 patient. Two patients complained of mild pain in left upper abdomen after the procedure that responded to intravenous tramadol; transabdominal US did not reveal any hematoma, pleural effusion or ascites. No other immediate complication was observed post-procedure. The cytology was adequate in all patients with hypoechoic FSL and all 8 (100\%) patients had granulomatous inflammation, with acid-fast bacilli being observed in 3 patients. The final diagnoses in these patients was tuberculosis in 6 patients (acid-fast bacilli in 3 patients, caseous necrosis in 2 patients, and tuberculin positivity along with response to antitubercular therapy in 1 patient), and sarcoidosis in 2 patients (non-caseating granulomatous inflammation along with lung parenchymal changes on high-resolution chest CT).

The cyst fluid was completely aspirated in all the 8 patients with cystic lesions. Seven patients had a single cystic lesion whereas 1 patient had multiple cystic lesions. The final diagnosis in patients with cystic lesions was pseudocyst in 5 patients and simple cyst in 3 patients. All the 5 patients with acute or chronic pancreatitis had elevated amylase and lipase levels in the aspirated fluid, whereas the aspirated fluid was non-diagnostic in patients with simple cysts. The diagnosis of simple cyst was made after the pathological examination of the splenectomy specimen in 2 patients and there was no change in the size of the cyst after a follow up of 38 months.

One patient with splenic pseudocyst had a massive gastrointestinal hemorrhage accompanied by hypotension 7 days after EUS-guided FNA and underwent successful surgery for bleeding from a splenic artery pseudoaneurysm. No other delayed major complication of EUS-guided FNA was encountered in any patient.

\section{Discussion}

Image-guided FNA is a safe and effective diagnostic modality for the cytological diagnosis of diseases affecting 
various organs. In spite of initial reluctance to use it for the diagnosis of splenic focal lesions, because of concerns about the risk of bleeding or splenic rupture, a number of studies published over last two decades have established the safety and efficacy of US-/CT-guided FNA of various FSL [7-9]. EUS is a relatively new imaging modality that provides highresolution images of organs adjacent to the gastrointestinal tract, as the transducer is placed close to the imaged organ with no intervening bowel gases. The spleen can also be visualized on EUS from the stomach and can be sampled directly with no intervening organ under real-time guidance. Moreover, a vessel-free needle track can also be chosen using color Doppler. However, the published experience on the role as well as the safety of EUS-guided FNA of FSL is limited.

Fritscher-Ravens et al reported the utility of EUS-guided FNA using a 22-G needle in 12 patients with FSL measuring $0.8-4.2 \mathrm{~cm}$ (median $1.4 \mathrm{~cm}$ ) [12]. This study excluded cystic lesions, and the authors reported that EUS-guided FNA resulted in a positive diagnosis in 10 of 12 patients (83\%). The only adverse effect reported was transient abdominal pain in one patient. Iwashita et al studied the diagnostic yield of EUSguided FNA using a 19-G needle in 5 patients suspected of splenic tumor [13]. Using a large-caliber needle, the authors were able to obtain pathological samples in all five cases and were also to perform flow cytometry, with the final diagnoses being lymphoma $(n=2)$, sarcoidosis $(n=2)$, and inflammatory pseudotumor $(n=1)$. As in the study by Fritscher-Ravens et al, in this study, too, there were no serious complications of EUS-guided FNA, with only 1 patient having mild abdominal pain the day after the procedure.

Eloubeidi et al also reported their experience of EUSguided FNA using a $22-\mathrm{G}$ needle in 6 patients with splenic masses (lymphoma and benign FSL each in 3 patients) [11]. The mean short- and long-axis diameters of the lesions were $37.8 \mathrm{~mm}$ and $45.6 \mathrm{~mm}$, respectively. EUS-guided FNA was performed successfully in all 6 patients and a correct diagnosis of lymphoma was made using flow cytometry in $2 / 3$ patients. Again, no complications of EUS-guided FNA were encountered in these 6 patients.

In contrast to these previously published studies, we evaluated the safety and efficacy of EUS-guided FNA in 16 cases that included both cystic and non-cystic splenic lesions. We were able to perform EUS-guided FNA successfully in all patients. The cytology was adequate in all 16 patients, with cytological or biochemical examination of aspirated material/fluid establishing the diagnosis in $81 \%$. Two patients complained of transient mild self-limiting pain in the left upper abdomen with normal transabdominal ultrasound. One patient with splenic pseudocyst had a massive gastrointestinal hemorrhage 7 days after EUS-guided aspiration, caused by an unrelated bleeding splenic artery pseudoaneurysm. FNA of cystic lesions may raise concern because of the risk of infection, pain and bleeding; however, most of the time, as is in other cystic lesions, the adverse effects are self-limiting and usually do not require any specific intervention [14].

Moreover, in contrast to previously published studies where the majority of patients had malignant FSL, all our patients had benign FSL that could be accurately diagnosed as well as

\section{Summary Box}

\section{What is already known:}

- Focal splenic lesions (FSL) are relatively rare and are caused by a variety of benign and malignant etiologies

- FSL can be diagnosed correctly using image-guided fine-needle aspiration (FNA)

- Endoscopic ultrasound (EUS) allows high-resolution imaging of the adjacent organs, including the spleen, with no hindrance from the bowel gases

- Limited experience suggests EUS-guided FNA of malignant FSL is a safe and accurate diagnostic modality

\section{What the new findings are:}

- EUS provides high-resolution images of the spleen that help in the evaluation of even small focal lesions

- EUS-guided FNA is a safe and effective diagnostic modality for evaluating focal cystic as well as non-cystic splenic lesions, also including benign lesions

medically managed, avoiding splenectomy in the majority of patients. Previously, US-guided splenic FNA has been reported to be a useful technique for the diagnosis of benign diseases such as tuberculosis [3]. There are also case reports describing the utility of EUS-guided FNA for the diagnosis of splenic tuberculosis $[15,16]$.

The small sample size and the retrospective study design are important limitations of our study. Notwithstanding these limitations, our study has shown that EUS provides highresolution images of the spleen that help in the evaluation of even small focal lesions. Moreover, EUS-guided FNA is a safe and effective diagnostic modality for evaluating focal cystic as well as non-cystic splenic lesions.

\section{References}

1. Wan YL, Cheung YC, Lui KW, Tseng JH, Lee TY. Ultrasonographic findings and differentiation of benign and malignant focal splenic lesions. Postgrad Med J 2000;76:488-493.

2. Goerg C, Schwerk WB, Goerg K. Splenic lesions: Sonographic patterns, follow-up, differential diagnosis. Eur $J$ Radiol 1991;13:59-66.

3. Handa U, Tiwari A, Singhal N, Mohan H, Kaur R. Utility of ultrasound-guided fine-needle aspiration in splenic lesions. Diagn Cytopathol 2013;41:1038-1042].

4. Kraus MD, Fleming MD, Vonderheide RH. The spleen as a diagnostic specimen: A review of 10 years' experience at two 
tertiary care institutions. Cancer 2001;91:2001-2009.

5. Quinn SF, vanSonnenberg E, Casola G, Wittich GR, Neff CC. Interventional radiology in the spleen. Radiology 1986;161:289-291.

6. Patel N, Dawe G, Tung K. Ultrasound-guided percutaneous splenic biopsy using an 18-G core biopsy needle: Our experience with 52 cases. Br J Radiol 2015;88:20150400.

7. Caraway NP, Fanning CV. Use of fine-needle aspiration biopsy in the evaluation of splenic lesions in a cancer center. Diagn Cytopathol 1997;16:312-316.

8. Kumar PV, Monabati A, Raseki AR, et al. Splenic lesions: FNA findings in 48 cases. Cytopathology 2007;18:151-156.

9. Gómez-Rubio M, López-Cano A, Rendón P, et al. Safety and diagnostic accuracy of percutaneous ultrasound-guided biopsy of the spleen: A multicenter study. J Clin Ultrasound 2009;37:445-450.

10. Sharma V, Rana SS, Bhasin DK. Endoscopic ultrasound guided interventional procedures. World J Gastrointest Endosc 2015;7:628-642.

11. Eloubeidi MA, Varadarajulu S, Eltoum I, Jhala D, Chhieng DC, Jhala NC. Transgastric endoscopic ultrasound-guided fine-needle aspiration biopsy and flow cytometry of suspected lymphoma of the spleen. Endoscopy 2006;38:617-620.

12. Fritscher-Ravens A, Mylonaki M, Pantes A, Topalidis T, Thonke F, Swain P. Endoscopic ultrasound-guided biopsy for the diagnosis of focal lesions of the spleen. Am J Gastroenterol 2003;98:1022-1027.

13. Iwashita T, Yasuda I, Tsurumi H, et al. Endoscopic ultrasoundguided fine needle aspiration biopsy for splenic tumor: A case series. Endoscopy 2009;41:179-182.

14. Zhu H, Jiang F, Zhu J, Du Y, Jin Z, Li Z. Assessment of morbidity and mortality associated with EUS-guided FNA for pancreatic cystic lesions: A system review and meta-analysis. Dig Endosc 2017 Feb 20. doi: 10.1111/den.12851. [Epub ahead of print]

15. Rana SS, Bhasin DK, Rao C, et al. Splenic tuberculosis diagnosed by endoscopic ultrasound-guided fine needle aspiration. Endosc Ultrasound 2012;1:167-168.

16. Nasa M, Choudhary NS, Guleria M, Puri R. Isolated splenic tuberculosis diagnosed by endoscopic ultrasound-guided fine needle aspiration. Indian J Tuberc 2017;64:134-135. 